\title{
Using of Salicylaldehyde Reagent in Spectrophotometric Determination of Niclosamide Via Schiff Base Reaction
}

\author{
Mohammed Mahmood Mohammed ${ }^{1}$, Othman Nabeel Sabeeh ${ }^{2,}$, , Al-Abady Faiz Muhseen ${ }^{1}$ \\ ${ }^{1}$ Department of Chemistry, College of Science, Tikrit University, Tikrit, Iraq \\ ${ }^{2}$ Department of Chemistry, College of Science, Mosul University, Mosul, Iraq
}

Email address:

Mohmahmoh981@yahoo.com (Mohammed M. M.),nsn20002004@uomosul.edu.iq (Othman N. S.),

faizal.abady@tu.edu.iq (Al-Abady F. M.)

${ }^{*}$ Corresponding author

\section{To cite this article:}

Mohammed Mahmood Mohammed, Othman Nabeel Sabeeh, Al-Abady Faiz Muhseen. Using of Salicylaldehyde Reagent in Spectrophotometric Determination of Niclosamide Via Schiff Base Reaction. Science, Technology \& Public Policy.

Vol. 5, No. 1, 2021, pp. 40-46. doi: 10.11648/j.stpp.20210501.14

Received: February 11, 2021; Accepted: March 1, 2021; Published: March 30, 2021

\begin{abstract}
The present method includes spectrophotometric determination of niclosamide (NICS) via Schiff base reaction in an alcoholic medium (ethanol) after reducing the nitro group in NICS by added zinc powder in an acidic medium to produce a primary amine group which can be coupled with the salicylaldehyde (SSA) reagent to give a yellow solution whose absorption is followed at the wavelength of $405 \mathrm{~nm}$. Beer's law limitation for the proposed method was in the range of concentrations of 4.0-30 $\mu \mathrm{g} . \mathrm{ml}^{-1}$. The molar absorbance value was $8.701 \times 10^{4} 1 \mathrm{~mol}^{-1} \mathrm{~cm}^{-1}$ and Sandell's sensitivity value was $0.0376 \mu \mathrm{g}$. $\mathrm{cm}^{-2}$. The effect of the reaction components was studied separately by changing one of the components and keeping the other constant, and the optimal conditions were chosen for all these studied components. The proposed method has been successfully applied for the determination of NICS in a pharmaceutical formulation (Yumesan tablets). The recovery percentage of the medicinal compound under study (niclosamide) from the tablet pharmaceutical preparation (Yumesan) via applying the suggested method was not less than $96.36 \%$, and the values of each of the low detection limit (LOD), the low quantitation limit (LOQ), the relative error percentage (RE\%), and the relative standard deviation percentage (RSD\%), their values were calculated as they are listed $0.9778 \mu \mathrm{g} . \mathrm{ml}^{-1}, 3.259 \mu \mathrm{g} . \mathrm{ml}^{-1},-3.61 \%$ and not more than $3.67 \%$ respectively.
\end{abstract}

Keywords: Niclosamide, Salicylaldehyde, Schiff base, Spectrophotometric, Yumesan Tablets

\section{Introduction}

Niclosamide is a chlorinated salicylanilide that is dosed orally, as it has anthelmintic and possibly anticancer activity. It has also been approved by the Food and Drug Administration was effective for various viral infections such as SARS (SARS-COV). Studies are being conducted on NICS to identify its possible clinical use in the handling of Coronavirus (COVID-19). NICS does not dissolve in water, but it is soluble in chloroform, ethanol, and acetone. NICS is considered harmless from a toxicological fact of view and completely free from undesirable effects, except for very rare gastrointestinal disturbances. NICS has a pale yellowish color and has the molecular formula is $\mathrm{C}_{13} \mathrm{H}_{8} \mathrm{Cl}_{2} \mathrm{~N}_{2} \mathrm{O}_{4}$ (M.wt=327.12 g. Mol. ${ }^{-1}$ ), and has the following chemical structure in Figure 1 [1-4].<smiles>O=C(Nc1ccc([N+](=O)[O-])cc1Cl)c1cc(Cl)ccc1O</smiles>

Figure 1. The chemical structure of NICS.

The main reagent used in the present work was salicylaldehyde (2-hydroxybenzaldehyde, ohydroxybenzaldehyde or benzaldehyde, 2-hydroxy). It is a colorless or pale yellow liquid with the odor of bitter almond, somewhat miscible with water. It has the molecular formula $\mathrm{C}_{7} \mathrm{H}_{6} \mathrm{O}_{2}$ (M.wt=122.12 g / mol.), and the chemical structure is shown below in Figure 2 [5]. 
Various techniques have been used to determine NICS, the most important of which are RP-HPLC [6, 7], RPHPLC and HPTLC [8], RP-HPLC and derivative spectrophotometric methods [9], LC-MS/MS [10], carbon nanoparticle/chitosan modified electrode for the squarewave voltammetry [11], differential pulse striping voltammetry [12], nanohybrid sensor [13]. Through the literary survey, a limited number of spectrophotometric methods included most of the methods included a process of reducing the nitro group to the amino group and then incorporating it into reactions with different reagents, for example fast red B salt [14], p-benzoquinone [15], 2,6dihydroxybenzoic acid [16] and N,N-dimethyl amino pbenzaldehyde [17]. An additional method included oxidation of NICS with ferric ion then coupling the liberated $\mathrm{Fe}^{+2}$ with 1.10- phenanthroline can be used [18].<smiles>O=Cc1ccccc1O</smiles>

Figure 2. Chemical structure of salicylaldehyde.

The present work included the simple and accurate spectrophotometric method of assay NICS using the Schiff base reaction after reduction of the nitro group and incorporating the R-NICS with SSA reagent.

\section{Experimental}

\subsection{Apparatus Used}

All absorption measurements were performed with a double beam Jasco V-630 Spectrophotometer and using 1 cm glass cells, also a HANNA $301 \mathrm{pH}$ meter and a Memmert water bath were used in the present investigation.

\subsection{Chemicals Used}

All chemicals used are of a high degree of purity.

\subsection{Solutions Used}

\subsubsection{Reducing Niclosamide (R-NICS) Solution (100 $\mu \mathrm{g} . \mathrm{ml}^{1}$ )}

This solution was prepared via dissolving $0.0100 \mathrm{~g}$ of pure NICS in $10 \mathrm{ml}$ of ethanol in a $50 \mathrm{ml}$ beaker, then after stirring and heating to dissolve all NICS, $5 \mathrm{ml}$ of hydrochloric acid $(1 \mathrm{M})$ and $0.1 \mathrm{~g}$ of zinc powder were added to the solution with stirring, then the mixture was placed in a water bath at boiling point for 15 minutes, then after cooling it was filtered into a $100-\mathrm{ml}$ volumetric flask and the volume was completed with absolute ethanol to the extent of the mark [17].

\subsubsection{Salicylaldehyde Reagent Solution (SSA, 10\%)}

This solution was prepared by transferring $10 \mathrm{ml}$ of concentrated SSA reagent to a $100 \mathrm{ml}$ volumetric flask, then the volume was complemented with absolute ethanol to the mark.

\subsubsection{Hydrochloric Acid Solution (1 M)}

This solution was prepared by diluting $8.4 \mathrm{ml}$ of concentrated hydrochloric acid

\subsubsection{Pharmaceutical Preparation Solution (100 $\left.\mu \mathrm{g} . \mathrm{ml}^{1}\right)$}

Three tablets (Yomesan, $500 \mathrm{mg}$ of NICS/tablet) were weighed (the average weight of one tablet was $0.8963 \mathrm{~g}$ ) and then crushed together, then $0.0179 \mathrm{~g}$ of powder was taken and dissolved in $10 \mathrm{ml}$ of ethanol with stirring and dissolving need heating, then $5 \mathrm{ml}$ of hydrochloric acid (1 M) were added to it, then $0.1 \mathrm{~g}$ of zinc powder with stirring then the beaker was lifted in a water bath at boiling point for 15 minutes and after cooling it was filtered in a $100 \mathrm{ml}$ volumetric flask and supplemented with absolute ethanol to the extent of the mark.

\section{The Procedure and Calibration Curve}

The standard curve of the proposed method for estimating NICS was studied by preparing a series of $5 \mathrm{ml}$ volumetric flasks and to each of them a different volume of the standard solution of R-NICS within the range $(20-150 \mu \mathrm{g}), 0.5 \mathrm{ml}$ of reagent SSA $(10 \%)$ then $0.6 \mathrm{ml}$ of concentrated sulfuric acid were added, and after waiting for 15 minutes, the volumes of these flasks were completed to the mark with absolute ethanol and the absorbance was measured against the blank solution at the wavelength of $405 \mathrm{~nm}$. The linear sequence of these concentrations was observed within this range, as shown in Figure 3. The molar absorptivity and Sandell's sensitivity were calculated and equal to $8.701 \times 10^{3} 1 . \mathrm{Mol}^{-1}$. $\mathrm{cm}^{-1}$ and $0.0376 \mu \mathrm{g} . \mathrm{cm}^{-2}$ respectively.

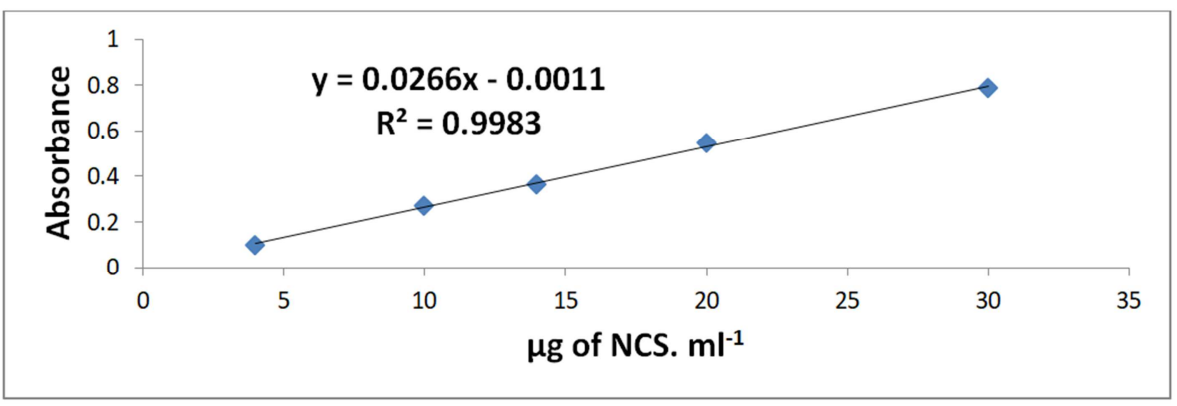

Figure 3. Standard calibration curve of niclosamide using the proposed method. 


\section{Results and Discussion}

\subsection{Preliminary Study}

$1 \mathrm{ml}$ of R-NICS $(100 \mu \mathrm{g}$.) was mixed with $0.2 \mathrm{ml}$ of SSA reagent $(10 \%)$ in a $5 \mathrm{ml}$ volumetric flask, then $0.4 \mathrm{ml}$ of concentrated sulfuric acid was added to the mixture and the solution was left for a waiting period ( 5 minutes) and then the volume completed with absolute ethanol to the mark, so it was noticed that the resulting solution gave a yellow color and the blank solution was colorless. The absorption spectrum was measured against its blank solution, and it gave the highest absorption at the wavelength of $406 \mathrm{~nm}$. Thus, this wavelength was adopted for the subsequent experiments.

\subsection{General Principle of the Method}

The general principle of the present method includes the reduction of NICS with zinc powder to convert the nitro group in it into a primary amine group and then this amine group condensate with carbonyl group of the SSA reagent to produce a yellow complex as shown in the following equations (see Figure 4).<smiles>C[14C](C)[14CH2]c1ccc(O)c(C(=O)Nc2ccc(N)cc2Cl)c1</smiles>

NIC<smiles>Nc1ccc(NC(=O)c2cc(Cl)ccc2O)c(Cl)c1</smiles>

R-NICS<smiles>[InH][I-]</smiles>

SSA

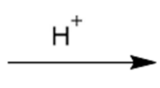<smiles>O=C(Nc1ccc(N=Cc2ccccc2O)cc1Cl)c1cc(Cl)ccc1O</smiles>

NICS-SSA condensate product (Yellow color)

Figure 4. The general reactions of the present method.

\subsection{Setting the Optimum Conditions of the Method}

The optimum conditions of the suggested method were studied in order to obtain high sensitivity and stability of the product, and thus the effects of each of the following parameters were studied:

\subsection{Study the Effect of Acid Type}

The effect of different types of acids on the reaction of the Schiff base was studied by adding I $\mathrm{ml}$ of R-NICS (100) to series of $5-\mathrm{ml}$ of volumetric flasks, then $0.2 \mathrm{ml}$ of SSA reagent solution $(10 \%)$, then $0.4 \mathrm{ml}$ of various types of concentrated acid Then, the volumes were completed with ethanol to the mark and the absorption was measured against the blank solution and the results were as shown in Table 1.

Table 1. The effect of acid type.

\begin{tabular}{lll}
\hline Concentrated acid used $(\mathbf{0 . 4 m l})$ & Absorbance & $\boldsymbol{\lambda}_{\max }(\mathbf{n m})$ \\
\hline $\mathrm{HCl}$ & 0.1068 & 384 \\
$\mathrm{HNO}$ & 0.2084 & 386 \\
$\mathrm{H}_{3} \mathrm{PO}_{4}$ & 0.1866 & 383 \\
$\mathrm{H}_{2} \mathrm{SO}_{4}$ & 0.2195 & 406 \\
$\mathrm{CH}_{3} \mathrm{COOH}$ & 0.0308 & 402 \\
\hline
\end{tabular}

Through the results in Table 1 , the reaction needs a strongly acidic medium, and sulfuric acid has been adopted for the rest of the subsequent experiments to give it the highest absorbance of yellow product.

\subsection{Study the Effect of the Amount of Concentrated Sulfuric Acid}

The effect of the volume of concentrated sulfuric acid was studied by preparing a series of 5-ml volumetric flasks each containing $1 \mathrm{ml}$ of R-NICS $(100 \mu \mathrm{g})$ with $0.2 \mathrm{ml}$ of SSA reagent solution (10\%) with different volumes of concentrated sulfuric acid. The volumes were completed with ethanol and the absorbance of each the solution was measured at the wavelength of $406 \mathrm{~nm}$ (Table 2).

Table 2. Effect of acid amount.

\begin{tabular}{lll}
\hline Concentrated sulfuric acid $(\mathbf{m l})$ & Absorbance & $\boldsymbol{\lambda}_{\max }(\mathbf{n m})$ \\
\hline 0.2 & 0.1831 & 411 \\
0.4 & 0.2105 & 405 \\
0.6 & 0.2682 & 404 \\
0.8 & 0.2684 & 404 \\
1.0 & 0.2566 & 403 \\
& 0.2270 (unstable) & 570 \\
1.5 & 0.2619 (unstable) & 570 \\
\hline
\end{tabular}


Through the results in Table 2, although the use of large volume $(1.0$ and $1.5 \mathrm{ml})$ of concentrated sulfuric acid caused a red-shift, but the stability was very weak. Therefore, the volume of $0.6 \mathrm{ml}$ of concentrated sulfuric acid was adopted for the rest of the subsequent experiments.

\subsection{Study of the Effect of Waiting Time after Adding Acid (Before Dilution)}

Several 5-ml volumetric flasks were taken and to each one $1 \mathrm{ml}$ of R-NICS $(100 \mu \mathrm{g})$ with $0.2 \mathrm{ml}$ of SSA reagent solution $(10 \%)$ were added, then $0.6 \mathrm{ml}$ of concentrated sulfuric acid with different waiting times for each sample, then the volume was completed with ethanol. The absorbance of each solution was measured versus its blank solution at the wavelength of $406 \mathrm{~nm}$, the results in Table 3 show that 15 minute was the optimum time to give complete oxidation, and it was fixed in the subsequent experiments.

Table 3. Effect of oxidation time.

\begin{tabular}{lllllll}
\hline $\begin{array}{l}\text { Oxidation } \\
\text { time (min.) }\end{array}$ & Immed. & $\mathbf{5}$ & $\mathbf{1 0}$ & $\mathbf{1 5}$ & $\mathbf{2 0}$ & $\mathbf{3 0}$ \\
\hline Absorbance & 0.2143 & 0.2328 & 0.2493 & 0.2680 & 0.2662 & 0.2660 \\
\hline
\end{tabular}

\subsection{Study the Effect of the Amount of SSA Reagent}

This study was conducted to identify the most an appropriate amount of the reagent, which gives the best value for the determination coefficient $\left(R^{2}\right)$ for different concentrations of R-NICS by preparing a series of $5 \mathrm{ml}$ volumetric flasks and adding to each of them different volumes $(0.2-2 \mathrm{ml})$ within different volume of SSA reagent solution (0.1-0.6 ml), then $0.6 \mathrm{ml}$ of concentrated sulfuric acid with a waiting period of 15 minutes, then the volumes were completed with absolute ethanol and the absorbance was measured against it is the blank solution at the wavelength of $404 \mathrm{~nm}$, the results were as in Table 4.

Table 4. The optimum amount of reagent.

\begin{tabular}{llllll}
\hline Reagent (SSA & \multicolumn{6}{l}{ Absorbance/ $\boldsymbol{\mu}$ of RNIC in 5 ml } \\
\cline { 2 - 6 }$(\mathbf{1 0} \%), \mathbf{m l})$ & $\mathbf{2 0}$ & $\mathbf{5 0}$ & $\mathbf{1 0 0}$ & $\mathbf{2 0 0}$ & $\mathbf{R}^{\mathbf{2}}$ \\
\hline 0.1 & 0.0420 & 0.1098 & 0.1530 & 0.3446 & 0.9842 \\
0.2 & 0.0899 & 0.1842 & 0.2651 & 0.5745 & 0.9881 \\
0.3 & 0.0735 & 0.2081 & 0.3210 & 0.5859 & 0.9900 \\
0.4 & 0.1361 & 0.2431 & 0.3980 & 0.8221 & 0.9953 \\
0.5 & 0.1401 & 0.3209 & 0.5489 & 1.0436 & 0.9988 \\
0.6 & 0.0736 & 0.2685 & 0.5143 & 0.9503 & 0.9945 \\
\hline
\end{tabular}

Through the results in Table 4, the optimum volume of the SSA reagent solution was $0.5 \mathrm{ml}$, and thus this volume was adopted in the subsequent experiments.

\subsection{The Effect of Solvent}

The effect of different types of solvents used in dilution on the absorption of the Schiff base product was studied by completed their volumes after adding the components of reaction to the extent of the mark with the solvent understudy, and the spectrum was measured for each of them against the blank solution, The results illustrated in Figure 5 and Table 5.

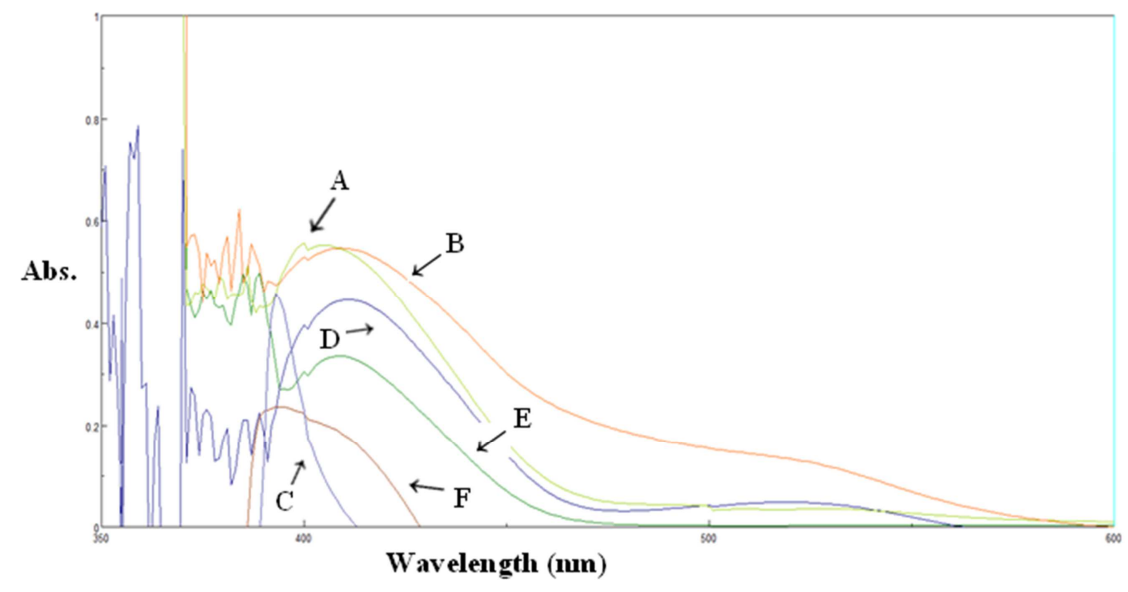

A: Ethanol, B: Water, C: Propanol, D: n-Butanol, E: Acetic acid, F: Methanol.

Figure 5. Effect of solvents on spectrum of Schiff's base.

Table 5. Effect of solvents.

\begin{tabular}{llll}
\hline Solvent & Absorbance & $\boldsymbol{\lambda}_{\max }$ & $\mathbf{C}, \mathbf{L} \cdot \mathbf{m o l}^{\mathbf{- 1}} \cdot \mathbf{c m}^{-1}$ \\
\hline Methanol & 0.2349 & 393 & 3915 \\
Ethanol & 0.551 & 405 & 9183 \\
Propanol & 0.4565 & 393 & 7608 \\
n-Butanol & 0.4448 & 411 & 7413 \\
Acetone & Turbid & & \\
Acetic acid & 0.3341 & 409 & 5568 \\
Water & 0.5455 & 409 & 9091 \\
\hline
\end{tabular}

The results are shown in Figure 2 and Table 5, although of the high absorption value resulting from the water, was excluded because the resulting Schiff base is completely unstable and the color quickly disappears, and thus ethanol use was retained for subsequent experiments.

\subsection{Study of the Addition Order}

Various order of reaction reagents addition were studied to identify the most suitable ones. Through the results shown in Table 6, it becomes clear to include that order (I) gives the best value of absorbance compared to the other orders, and it is the order followed in the rest of the previous experiments, 
so it was maintained.

Table 6. Order of addition.

\begin{tabular}{ll}
\hline Order of addition & Absorbance \\
\hline (I): $\mathrm{NCS}+\mathrm{R}+\mathrm{H}^{+}+$Ethanol & 0.5613 \\
(II): $\mathrm{NCS}+\mathrm{H}^{+}+\mathrm{R}+$ Ethanol & 0.4663 \\
(III): $\mathrm{NCS}+$ Ethanol $+\mathrm{H}^{+}+\mathrm{R}$ & 0.5107 \\
(IV): $\mathrm{NCS}+$ Ethanol $+\mathrm{R}+\mathrm{H}^{+}$ & 0.4411 \\
(V): $\mathrm{R}+\mathrm{H}^{+}+\mathrm{NCS}+$ Ethanol & 0.5422 \\
\hline
\end{tabular}

\subsection{Study the Effect of Time on the Stability of the Schiff}

\section{Base Formed}

The stability of the Schiff base product with time was studied (By following the change of absorbance over time) for two different concentrations of R-NICS over a period of 60 minutes, starting from the moment of completion of the additions and complementing the volume with ethanol, the results as shown in Table7.

Table 7. Effect of time on stability.

\begin{tabular}{lll}
\hline \multirow{2}{*}{ Time (min.) } & \multicolumn{2}{c}{ Absorbance / $\boldsymbol{\mu g}$ RNICS } \\
\cline { 2 - 3 } & $\mathbf{5 0}$ & $\mathbf{1 0 0}$ \\
\hline Immediately & 0.2689 & 0.5406 \\
5 & 0.2744 & 0.5528 \\
10 & 0.2722 & 0.561 \\
15 & 0.2741 & 0.5616 \\
20 & 0.274 & 0.5509 \\
25 & 0.2732 & 0.5501 \\
30 & 0.2723 & 0.5497 \\
35 & 0.2711 & 0.5483 \\
40 & 0.2606 & 0.547 \\
45 & 0.2599 & 0.5443 \\
50 & 0.2586 & 0.5423 \\
55 & 0.2562 & 0.5418 \\
60 & 0.2566 & 0.5402 \\
\hline
\end{tabular}

From the results shown in the table above, it becomes clear that the Schiff base complex has good stability and with an accepted error of $\leq 5 \%$.

\section{Summary of all Optimum Conditions.}

After studying the optimum conditions for the proposed method, a summary of these conditions, which have been installed, was included in Table 8.

Table 8. The Optimum Conditions of the Method

\begin{tabular}{ll}
\hline Variables & The optimum conditions \\
\hline $\mathrm{pH}$ & Acidic \\
Type and amount of acid (Conc.). & $\mathrm{H}_{2} \mathrm{SO}_{4}, 0.6 \mathrm{ml}$ \\
Amount of SSA reagent $(10 \%)$. & $0.5 \mathrm{ml}$ \\
$\lambda_{\max }(\mathrm{nm})$ & 405 \\
Medium of reaction. & Ethanol \\
\hline
\end{tabular}

\subsection{Final Absorption Spectrum}

After completing the study of optimum conditions, the final absorption spectrum was studied by preparing a solution containing $1 \mathrm{ml}$ of an R-NICS in a volumetric flask of $5 \mathrm{ml}$ and adding to it $0.5 \mathrm{ml}$ of the SSA reagent $(10 \%)$, then $0.6 \mathrm{ml}$ of concentrated sulfuric acid, after waiting for 15 minute complete the volume to the mark with absolute ethanol. A spectral scan of 350-700 nm was taken, and the results were as shown in Figure 6.

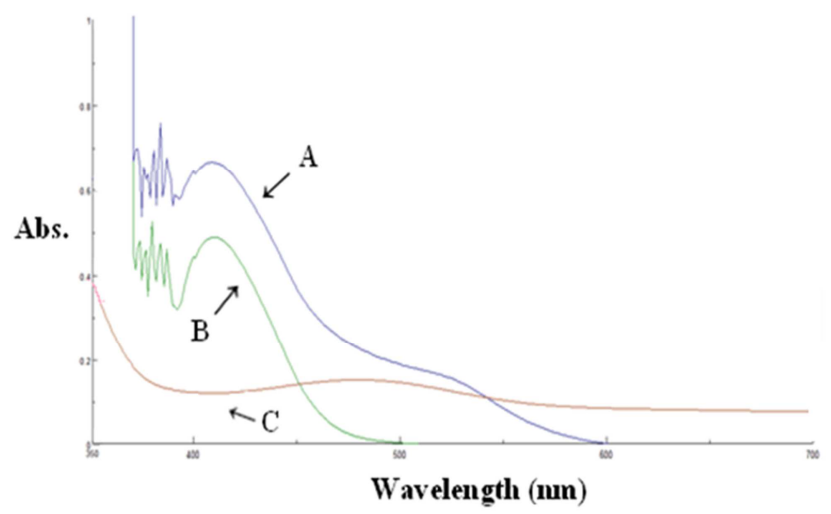

Figure 6. Spectrum of NICS-AAS (Schiff base):(A) Sample versus distilled water. (B) Sample versus blank.(C) Blank versus distilled water.

\subsection{Accuracy and Precision}

The values of the relative error and the relative standard deviation were calculated for three different concentrations of R-NICS by three readings for each of them, and the results were as in Table 9.

Table 9. Calculations of accuracy and precision values of standard NICS.

\begin{tabular}{lllll}
\hline Sample & $\begin{array}{l}\text { Amount } \\
\text { taken, } \boldsymbol{\mu g}\end{array}$ & Recovery* & RE\% & RSD\% \\
\hline Standard & 20 & 103.60 & +3.603 & 0.890 \\
niclosamide & 50 & 102.99 & +2.995 & 3.151 \\
solution $(100 \mu \mathrm{g} / \mathrm{ml})$ & 100 & 100.90 & +0.896 & 1.495 \\
\hline
\end{tabular}

* Average of three determinations.

It becomes clear from the results in Table 9 that the proposed method for determining NICS can be applied successfully. Whereas, the values of ER \%, which expresses accuracy, and $\mathrm{RSD} \%$, which expresses precision, are less than $\pm 5 \%$, so the method is accurate and precise.

\subsection{Application Part}

The application of the suggested method was performed on tablet form of NICS (Yomesan). Two series of 5-ml volumetric flasks were prepared, and different quantities of standard R-NICS solution $(0-100 \mu \mathrm{g})$ were added to the flasks and then added $0.25 \mathrm{ml}$ of the R-NICS drug standard solution $\left(100 \mu \mathrm{g} . \mathrm{ml}^{-1}\right)$ to each flask of the first series, as well as $0.5 \mathrm{ml}$ of the $\mathrm{r}$ R-NICS drug standard solution for each flask of the second series then added to each of the two series flasks $0.5 \mathrm{ml}$ of SSA reagent $(10 \%)$ and $0.6 \mathrm{ml}$ of concentrated sulfuric acid and then, after waiting for 15 minutes, the volumes of these flasks were completed to the mark with absolute ethanol and the absorbance was measured against the blank solution at the wavelength of $405 \mathrm{~nm}$. (see Figure 7).

From the two straight-line equations in Figure 4, the recovery values, the relative error, and the relative standard deviation of the pharmaceutical preparation (tablets) under 
study were calculated and for three repeated solutions for each of the two previously mentioned concentrations of R-

NICS $(25$ and $50 \mu \mathrm{g})$, the results were as in Table 10.

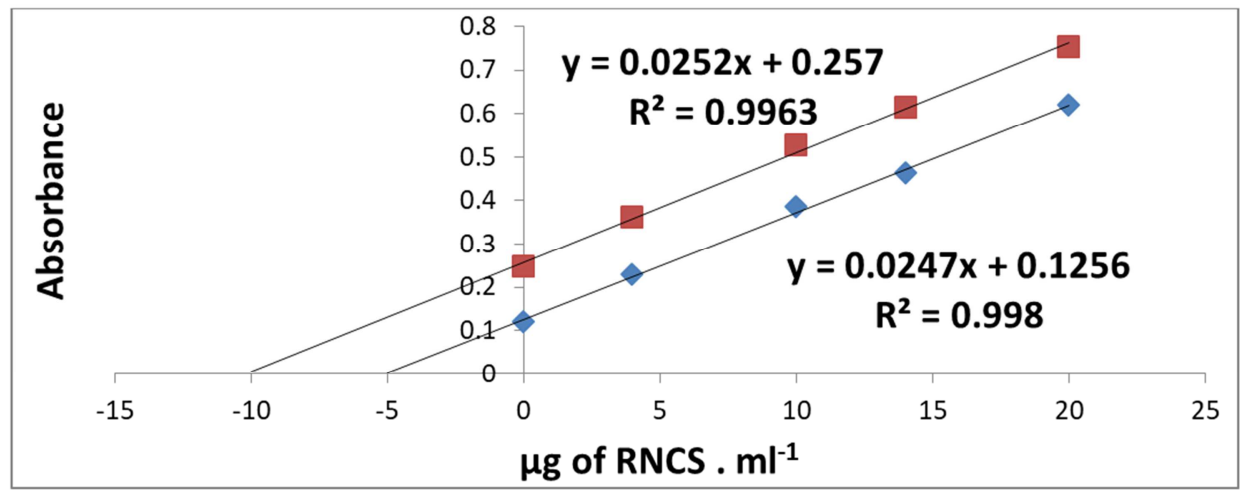

Figure 7. Standard addition plot.

Table 10. Calculations of accuracy and precision values of tablets.

\begin{tabular}{lllll}
\hline Drug & $\begin{array}{l}\text { Amount } \\
\text { taken, } \boldsymbol{\mu g}\end{array}$ & Recovery* & RE\% & RSD\% \\
\hline Yomesan/tablet & 25 & 101.70 & 1.70 & 3.67 \\
$(100 \mu \mathrm{g})$ & 50 & 101.98 & 1.98 & 3.17 \\
\hline
\end{tabular}

* Average of three determinations.

Through the results in Table 10, we can observe the accomplishment of the proposed method for estimating NICS in its pharmaceutical preparation (Yomesan/tablet), as the recovery values, $\mathrm{RSD} \%$, and $\mathrm{RE} \%$ are within the analytical permissible values.

\subsection{Comparison of the Methods Used in Determination of NICS}

Comparison of some of the analytical parameters of the proposed method for determination of NICS with the same of other methods. The results as shown in Table 11.

Table 11. Comparison of some analytical parameter of methods used in determination of NICS.

\begin{tabular}{|c|c|c|c|}
\hline Analytical Parameter & Present method & Literature method $^{(17)}$ & Literature method $^{(16)}$ \\
\hline Type of reaction & Schiff's base & Schiff's base & Diazotization \\
\hline $\max (\mathrm{nm})$ & 405 & 454 & 456 \\
\hline Reagent & Salicylaldehyde & $p$-N,N- dimethylaminobenzaldehyde & 2,6-Dihydroxybenzoic acid \\
\hline Color & Yellow & Yellow & Yellow \\
\hline Molar absorptivity (L.mole $\left.{ }^{-1} \cdot \mathrm{cm}^{-1}\right)$ & $8.701 \times 10^{3}$ & $3.369 \times 10^{4}$ & $2.36 \times 10^{4}$ \\
\hline Sandell's sensitivity $\left(\mu \mathrm{g} / \mathrm{cm}^{2}\right)$ & 0.0376 & 0.0097 & 0.0139 \\
\hline Range of determination $\left(\mu \mathrm{g} \cdot \mathrm{ml}^{-1}\right)$ & $4.0-30$ & $1.0-17$ & $0.5-30$ \\
\hline Determination coefficient & 0.9983 & 0.9984 & 0.9995 \\
\hline Medium of reaction. & Ethanol & Methanol & Aqueous \\
\hline $\mathrm{pH}$ & Acidic & Acidic & Basic \\
\hline $\mathrm{RSD} \%$ & $0.890-3.151$ & $0.205-0.616$ & - \\
\hline Application of the method & $\begin{array}{l}\text { Pharmaceutical preparation } \\
\text { (tablets) }\end{array}$ & $\begin{array}{l}\text { Pharmaceutical and veterinary } \\
\text { preparations }\end{array}$ & $\begin{array}{l}\text { Pharmaceutical preparation } \\
\text { (tablets) }\end{array}$ \\
\hline
\end{tabular}

Through the results shown in Table 11, we conclude that the proposed method is no less important in terms of sensitivity and good acceptability for application in the determination of NICS in pharmaceutical formulation (Tablet).

\section{Conclusions}

Through the results obtained and proven above, we conclude the possibility of applying the proposed method for spectrophotometric determination of NICS in its pharmaceutical formulation (Yomesan tablets) and with its satisfactory results after reducing the NICS and then condensation with the SSA reagent to form a yellow Schiff base solution, the intensity is proportional to the concentration of NICS in the Yomesan tablets.

\section{References}

[1] Chen, W., Mook Jr, R. A., Premont, R. T., \& Wang, J. (2018). Niclosamide: Beyond an antihelminthic drug. Cellular signalling, 41, 89-96.

[2] National Center for Biotechnology Information (2020). PubChem Compound Summary for CID 4477, Niclosamide. Retrieved December 17, 2020 from https://pubchem.ncbi.nlm.nih.gov/compound/Niclosamide.

[3] Liu, C., Lou, W., Zhu, Y., Nadiminty, N., Schwartz, C. T., Evans, C. P., \& Gao, A. C. (2014). Niclosamide inhibits androgen receptor variants expression and overcomes enzalutamide resistance in castration-resistant prostate cancer. Clinical cancer research, 20 (12), 3198-3210. 
[4] British Pharmacopeia on CD-ROM. System Simulation Ltd, the Stationary Office Ltd, London, 2009.

[5] National Center for Biotechnology Information (2020). PubChem Compound Summary for CID 6998, Salicylaldehyde. Retrieved December 29, 2020 from https://pubchem.ncbi.nlm.nih.gov/compound/Salicylaldehyde.

[6] Cholifah S, Farina Kartinasari W, Indrayanto G. Simultaneous HPLC determination of levamisole hydrochloride and anhydrous niclosamide in veterinary powders, and its validation. Journal of liquid chromatography \& related technologies. 2007 Nov 1; 31 (2): 281-91.

[7] Murugan, S., Upendra, J. C., \& Babu, M. N. (2016). RPHPLC Method for Simultaneous Estimation of Albendazole and Niclosamide in Oral Suspension for Veterinary Use. Research Journal of Pharmacy and Technology, 9 (1), 27-32.

[8] Paghadar, C., \& Vadia, N. H. (2019). Development and validation of stability indicating RP-HPLC and HPTLC for determination of Niclosamide in bulk and in synthetic mixture. Arabian Journal of Chemistry, 12 (8), 1803-1814.

[9] Shah, U., Gandhi, A., \& Dawawala, T. (2016). Reverse phase HPLC and derivative spectrophotometric methods for simultaneous estimation of fenbendazole and niclosamide in pharmaceutical dosage form. Journal of the Chilean Chemical Society, 61 (2), 2999-3004.

[10] Caldow, M., Sharman, M., Kelly, M., Day, J., Hird, S., \& Tarbin, J. A. (2009). Multi-residue determination of phenolic and salicylanilide anthelmintics and related compounds in bovine kidney by liquid chromatography-tandem mass spectrometry. Journal of Chromatography A, 1216 (46), 82008205 .

[11] Ghalkhani, M., \& Shahrokhian, S. (2010). Application of carbon nanoparticle/chitosan modified electrode for the square-wave adsorptive anodic striping voltammetric determination of Niclosamide. Electrochemistry Communications, 12 (1), 66-69.

[12] Yao, Y., Zhang, L., Duan, X., Xu, J., Zhou, W., \& Wen, Y. (2014). Differential pulse striping voltammetric determination of molluscicide niclosamide using three different carbon nanomaterials modified electrodes. Electrochimica Acta, 127, 86-94.

[13] Zhang, Z., Yao, Y., Xu, J., Wen, Y., Zhang, J., \& Ding, W. (2017). Nanohybrid sensor based on carboxyl functionalized graphene dispersed palygorskite for voltammetric determination of niclosamide. Applied Clay Science, 143, 5766 .

[14] Abul Khier, A., Elhenawee, M. M., \& Elmasry, M. S. (2008). Spectrophotometric method for the determination of some drugs using fast red B salt. E-journal of chemistry, 5.

[15] Abdel Fattah, S. A. (1997). Spectrophotometric determination of niclosamide using p-benzoquinone. Spectroscopy letters, 30 (5), 795-804.

[16] Othman, N. S. and Sultan, S. H. (2014). Spectrophotometric determination of niclosamide by prior reduction and subsequent diazotization-coupling with 2, 6-dihydroxybenzoic acid-application to tablets. Rafidain Journal of Science, 25 (1), 40-52.

[17] Othman, N. S., and Saleem, I. T. (2019). Spectrophotometric determination of niclosamide Via Schiff's base formulations in pharmaceutical and veterinary preparations. Revista Innovaciencia, 7 (1), 1-9.

[18] Othman, N. S., and Sultan, S. H. (2018). Indirect spectrophotometric determination of niclosamide in pharmaceutical preparations. Journal of Education and Science, 27 (3), 1-18. 